\title{
Rehabilitation of Marine Concrete Structure with Under-Water Hydrodemolition and Sprayed Concrete
}

\author{
Kyong-Ku YUN ${ }^{1, *}$, Kyeo-Re $\mathrm{Lee}^{2}$, Seung-Yeon $\mathrm{HAN}^{2}$, Yong-Gon $\mathrm{KIM}^{3}$, and Soo-Ahn $\mathrm{KWON}^{4}$ \\ ${ }^{1}$ Professor, Civil Engineering Department, Kangwon National University, S. Korea \\ ${ }^{2}$ Graduate Student, Civil Engineering Department, Kangwon National University, S. Korea \\ ${ }^{3}$ CEO, Daesang E\&C, S. Korea \\ ${ }^{4}$ Senior Research Fellow, Korea Institute of Construction Technology, S. Korea
}

\begin{abstract}
Hydrodemolition is a method of surface preparation using high-pressure water jets. Hydrodemolition cutting depth is dependent on the length of time that the water jet is directed at the concrete surface that determines the depth of removal, and contact time is controlled at the robotic cutter. During hydrodemolition concrete removal, the cement matrix is removed from the aggregate. This paper describe on the test results of under-water hydrodemolition which was done on a prefabricated concrete basin. A very simple and economic method for repairing the damaged concrete structures is a using a sprayed concrete, which is some times called as shotcrete. This paper, also, describe on the test results of sprayed concrete for the rehabilitation of marine concrete structure.
\end{abstract}

\section{Introduction}

Concrete structures have a wide application in marine environment. The major types of these marine structures are piers, concrete breakwaters and concrete platforms. Piers are common types of concrete structures that are built on posts extending from land to water, used as a landing place for ships, an entertainment area, a strolling place, etc. Pier columns are frequently damaged by harsh marine environment, resulted in cracking, spalling, scaling and breaking, as shown in Figure 1.

Hydrodemolition is a very good method of surface preparation for the damaged concrete structure using highpressure water jets. A hydrodemolition system consists of highpressure water pump; a robotic cutting head; and a trailer. Hydrodemolition cutting depth is dependent on the length of time.

During hydrodemolition concrete removal, the cement matrix is removed from the aggregate, leaving bulk debris of sand and aggregate to be collected and disposed. Figure 2 shows examples of hydrodemolition applications at marine structures. This paper describe on the test results of underwater hydrodemolition at a pre-fabricated concrete basin.

Spray applied mortar or concrete have become used extensively in the repair of concrete structures. Many developments in sprayed concrete technology since 2000 have enhanced shotcreting capabilities. This sprayed concrete has good volume stability, good freeze-thaw durability, and very low chloride permeability. Silica fume usage also made some progress in many applications. Shotcrete has traditionally been used in mining and tunnelling and rock stabilization. More recently shotcrete has been used in concrete repair, restoration or rehabilitation.

The shotcrete process is suitable in a number of concrete rehabilitation works because of such as: where formwork is not practical; where normal casting into formwork can't be employed; where a thin and/or variable thickness layer is required ; where access to the work area is difficult. This paper, also, describe on the application of cellular sprayed concrete into the rehabilitation of marine concrete structure.

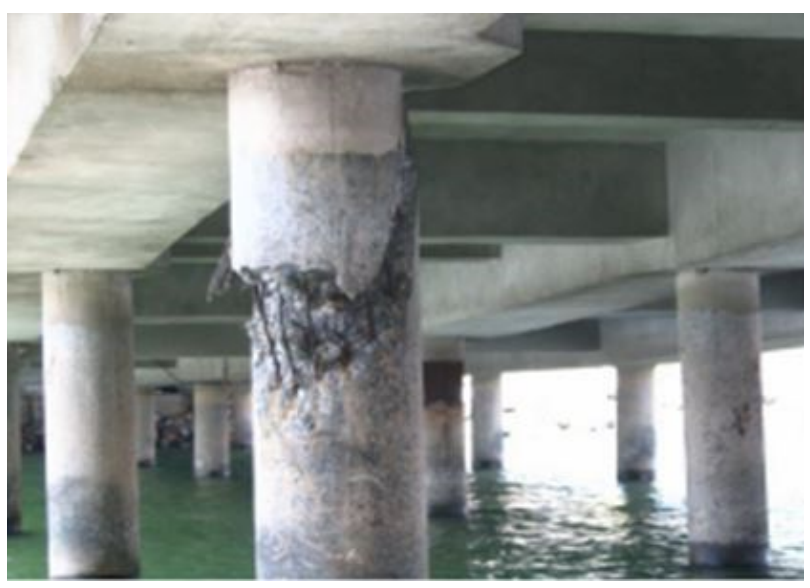

Figure 1 Distress example at marine RC pier column

\section{Hydrodemolition test and results}

\subsection{Mock-up test plan}

The objective of hydrodemolition mock-up test was to investigate and compare the hydrodemolition cutting performance in air and under water. The main experimental variables were cutting conditions (in air/ under water) and the nozzle height $(30 \mathrm{~mm} / 60 \mathrm{~mm}$ height).

\footnotetext{
* Corresponding author: kkyun@kangwon.ac.kr
} 
Figure 3 show the concept of mock-up test at a sloped concrete basin for testing at both of in air and under water. Figure 4 illustrates the concrete basin with mock-up test conditions: in water or under water conditions with nozzle height from bottom. The size of concrete basin was $5,000 \mathrm{~mm}$ by $3,000 \mathrm{~mm}$.
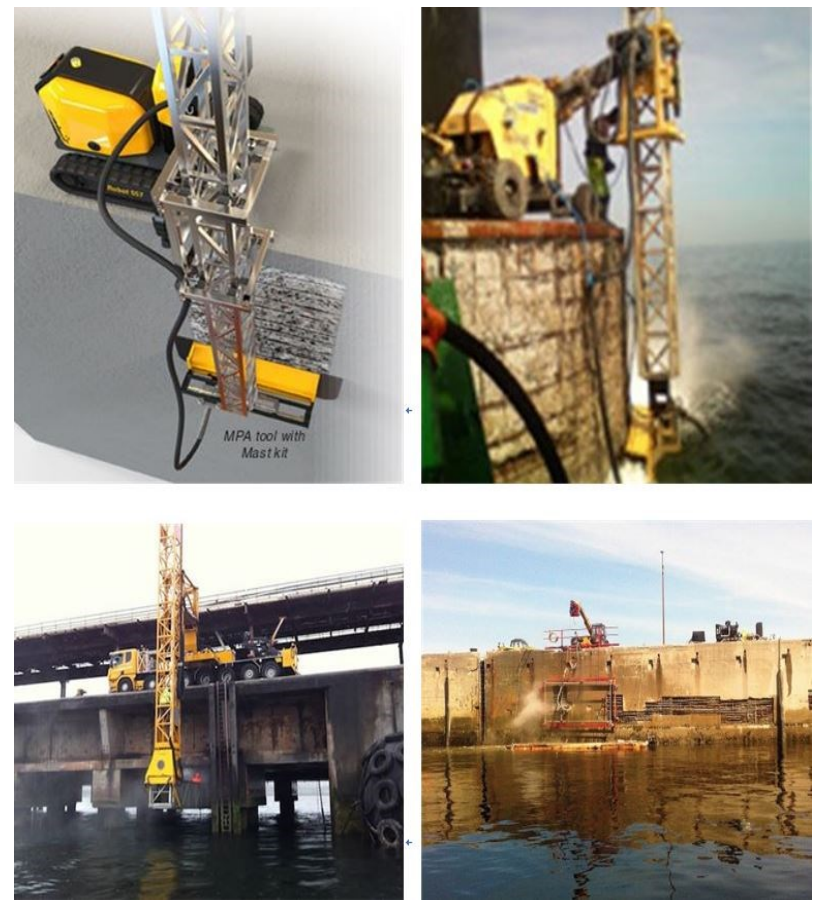

Figure 2 Application examples of hydrodemolition at marine concrete structures

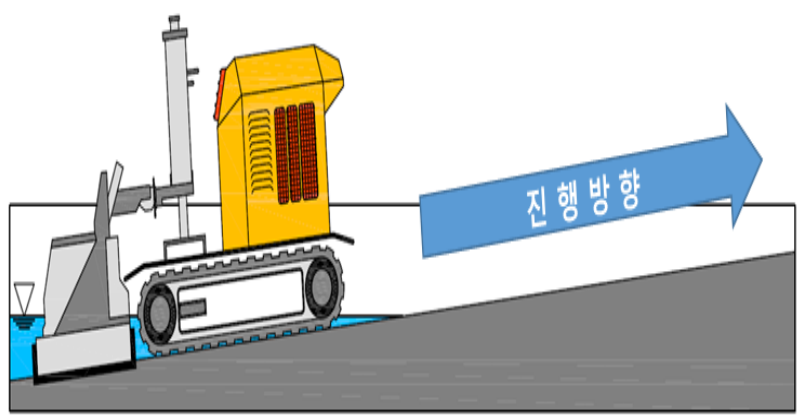

Figure 3 Concept of hydrodemolition mock-up test

\begin{tabular}{|c|c|c|}
\hline 4 & $1090 \mathrm{~mm}$ & $1475 \mathrm{~mm}$ \\
\hline $2450 \mathrm{~mm}$ & $\begin{array}{c}\text { C } \\
\text { under water } \\
6 \mathrm{~cm} \text { high nozzle }\end{array}$ & $\begin{array}{c}\text { A } \\
\text { under water } \\
\text { 3cm high nozzle }\end{array}$ \\
\hline $2450 \mathrm{~mm}$ & $\begin{array}{c}\text { D } \\
\text { in air } \\
6 \mathrm{~cm} \text { high nozzle }\end{array}$ & $\begin{array}{c}\text { B } \\
\text { in air } \\
3 \mathrm{~cm} \text { high nozzle }\end{array}$ \\
\hline
\end{tabular}

Figure 4 Hydrodemolition mock-up test lay out

A hydrodemolition system consists of High-pressure water pump(s); a robotic cutting head; and A support vehicle or trailer. The trailer carries the (1) pump; (2) cutting equipment and vehicle; (3) spare parts and tools; and (4) fuel and water tanks. Figure 5 shows the test processes of hydrodemolition. Water was supplied to the robotic machine from a high-pressure pump (about $1,100 \mathrm{bar}$ ) with high rate of flows (about $150 \mathrm{lpm}$ ). There are five parameters that determine the quality and depth of removal: Rotation speed of the nozzle; angle of the nozzle to the surface; height of the nozzle above the surface; traverse speed and advance distance.

\subsection{Hydrodemolition test results}

Figure 6 and 7 show the hydrodemolition cutting results in air and under water. The cutting shows that the higher nozzle height, the less cutting. The cutting depth was a little smaller at under water. However, the overall pattern and cutting depth was about the expected ranges. It was verified that the under-water hydrodemolition would be possible as expected.

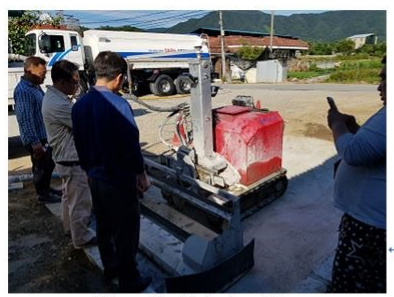

Set-up for Hydrodemolition

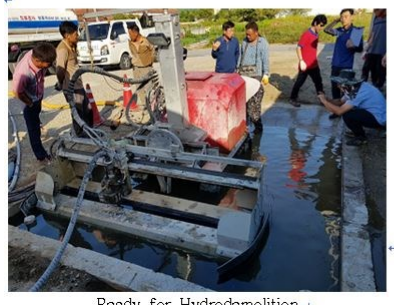

Ready for Hydrodemolition

Figure 5 Hydrodemolitoon test processes

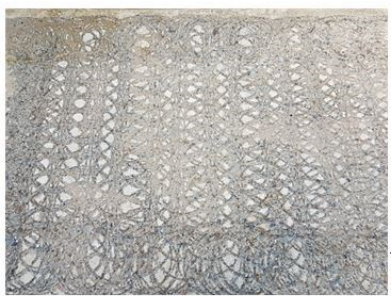

(1) Under water with $30 \mathrm{~mm}$ nozzle height $\downarrow$

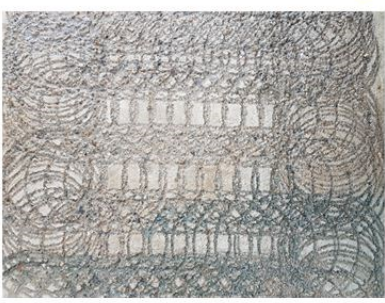

(3) Under water with $60 \mathrm{~mm}$ nozzle height $\downarrow$

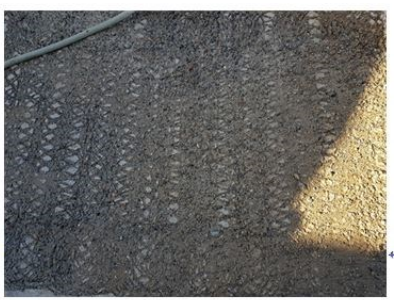

(2) In Air with $30 \mathrm{~mm}$ nozzle height $\downarrow$

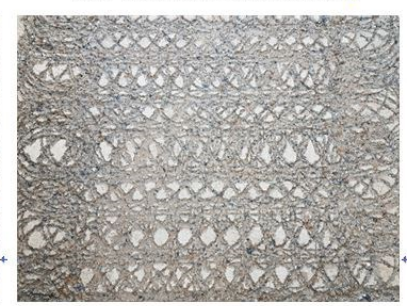

(4) In air with $60 \mathrm{~mm}$ nozzle height $\downarrow$
Figure 6 Results of hydrodemolition cutting pattern 


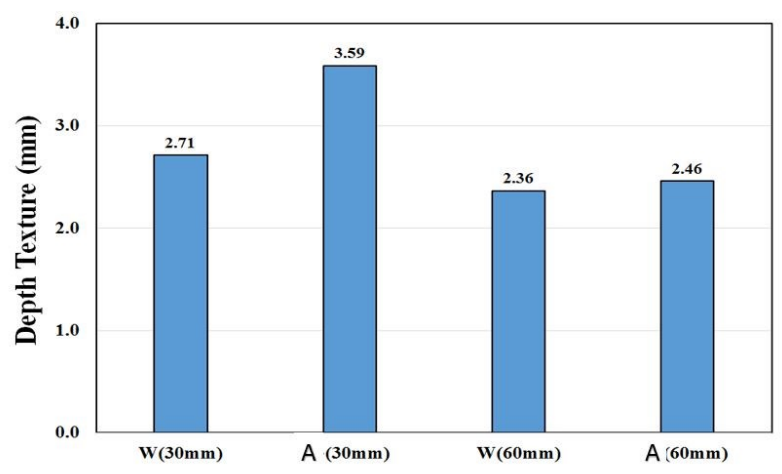

Figure 7 Results of hydrodemolition cutting depth

\section{Shotcrete test and results}

\subsection{Shotcrete test plan}

The main experimental variable was a substitution ratio of silica fume by $6,810 \%$. Table 1 shows an experimental variable and mix proportion of shotcrete.

Ordinary Portland cement (OPC) was used in all the shotcrete mixtures, satisfying KS L 5201(5). The fineness of OPC was $3,400 \mathrm{~cm}^{2} / \mathrm{g}$, density was $3.15 \mathrm{~g} / \mathrm{cm}^{3}$. The maximum size of coarse aggregate was $10 \mathrm{~mm}$. The combined aggregates of crushed fine and coarse aggregates were sampled and analysed to have the specific gravity of 2.82 and fineness modulus of 3.73 .

The tests for hardened concrete included compressive strength using a cylinders of $100 \times 200 \mathrm{~mm}$ and flexural strength using a beam of $100 \times 450 \mathrm{~mm}$ according to Korean standards(5). These tests were performed to monitor strength development for the concrete mixtures at 28 days and 56 days. The rapid chloride permeability test was performed according to ASTM C 1202 (equivalent to AASHTO T277) to evaluate the relative permeability of shotcrete(3).

Table 1 Mix Proportion of shotcrete

\begin{tabular}{|c|c|c|c|c|c|c|c|c|c|}
\hline & \multirow{2}{*}{$\begin{array}{l}\text { W/C } C_{4} \\
(\%)\end{array}$} & \multirow{2}{*}{$\begin{array}{l}\text { S/a, } \\
(\%)\end{array}$} & \multicolumn{5}{|c|}{ Unit Weight $\left(\mathrm{kg} / \mathrm{m}^{\mathrm{s}}\right)_{+}$} & \multirow{2}{*}{$\begin{array}{l}\text { WR, } \\
(\%),\end{array}$} & \multirow{2}{*}{$\begin{array}{l}\mathrm{Air}_{+} \\
(\%)_{+}\end{array}$} \\
\hline & & & $\mathrm{w}_{+} \mathrm{l}$ & $\mathrm{C}_{4} \mathrm{I}$ & $s+1$ & $\mathrm{G}, \mathrm{l}$ & S.F, & & \\
\hline Control & \multirow{4}{*}{40} & \multirow{4}{*}{60} & \multirow{4}{*}{ لـ484 } & لـ & | 1111 & 376 & لـ & لـ & لـ- \\
\hline $\mathrm{SF} 6+$ & & & & 432 & 1065 & 361 & $28+$ & 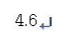 & 30 \\
\hline $\mathrm{SF}_{+}$ & & & & ل & 1050 & ل 355 & $37 \sqrt{1}$ & $5.0 \mathrm{~A}$ & 304 \\
\hline $\mathrm{SF} 10+$ & & & & 414 & 1035 & 350 & 46,1 & ل5.5 & 30, \\
\hline
\end{tabular}

\subsection{Shotcrete test results}

The compressive test results at 28 days and 56 days are shown in the Figure 8 . They increased as the content of silica fume increased. It was the highest at $10 \%$ of silica fume content as $62.7 \mathrm{MPa}$ at 56 days, while it was the lowest at OPC sample as $49.1 \mathrm{MPa}$ at 28 days.

The flexural test result at 28 days is shown in the Figure 9. They increased as the content of silica fume increased. It was the highest at $10 \%$ of silica fume content as $8.8 \mathrm{MPa}$, while it was the lowest at $\mathrm{OPC}$ sample as $7.9 \mathrm{MPa}$ at 28 days. This results would be due to the Pozzolan effect of silica fume at concrete.

The results of rapid chloride permeability test at 28 days are shown in the Figure 10. It was measured as 7,427 coulombs at control specimen of OPC and as 951, 753,665 coulombs at 6,8 and $10 \%$ of silica fume content, respectively. It decreased from $100 \%$ of OPC to $13 \%, 10 \%$, and $9 \%$ of at 6,8 and $10 \%$ of silica fume content, respectively.

The rapid chloride permeability test rated the control specimen as "high" while the silica fume specimen as "very low" according to ASTM C 1201(1,3). Therefore silica fume admixture affected into the rapid chloride permeability in a better way.

Lifetime estimation of concrete structures due to chloride in seawater starts from commencing time estimation of corrosion of inner reinforcing steels. Therefore, in concerning case of shotcrete structures, commencing time of corrosion of major reinforcing steels by penetration and diffusion of chloride ions in seawater to concrete inside was estimated to evaluate structures' lifetime.

Berke $(6,7)$ studied relationship of accelerating test of chloride permeability (RCPT) measured in accordance with ASTM C 1202 and Chloride Diffusion Coefficients measured in accordance with NT Build 492 and announced as follows.

$\mathrm{D}_{\mathrm{t}}=0.0103 \times 10-12 \times($ Coulombs $) 0.84\left(\mathrm{~m}^{2} / \mathrm{s}\right)$

Herein, Dt is Chloride Diffusion Coefficient, Coulombs is Passing Quantity of Electric Charge measured according to ASTM C1202.

The chloride diffusion coefficient was determined by Berke's method, and the durable life time against chloride was estimated by KCI, ACI and FIB methods.

The expected life time was estimated based on the calculated diffusion coefficient using the RCPT data. The life cycle was estimated as 62 years from KCI, 112 years from FIB code and 103 years from ACI codes. The samples with silica fume showed an excellent tendency to that of control at durability tests.

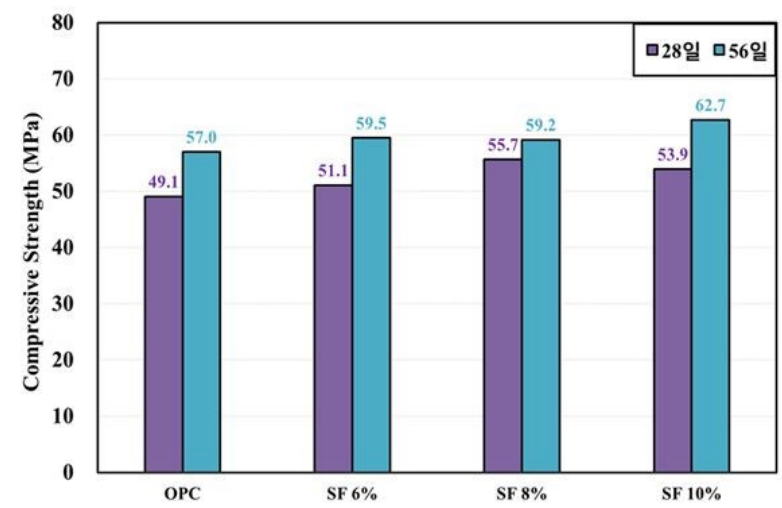

Figure 8 Results of shotcrete compressive strength 


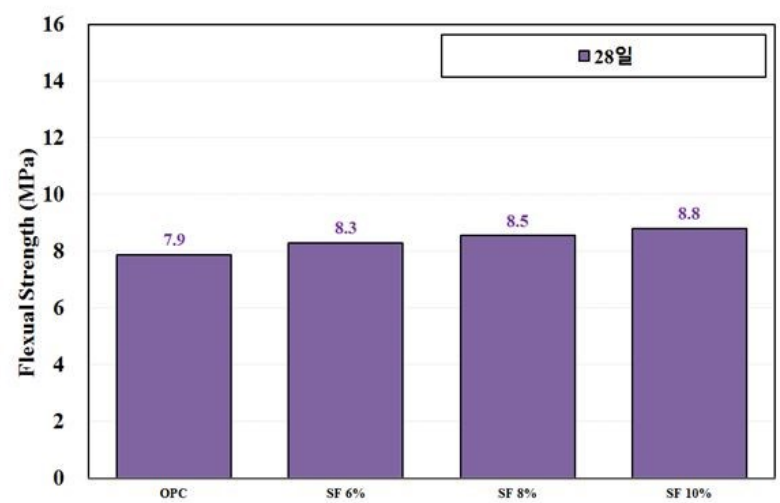

Figure 9 Results of shotcree flexural strength

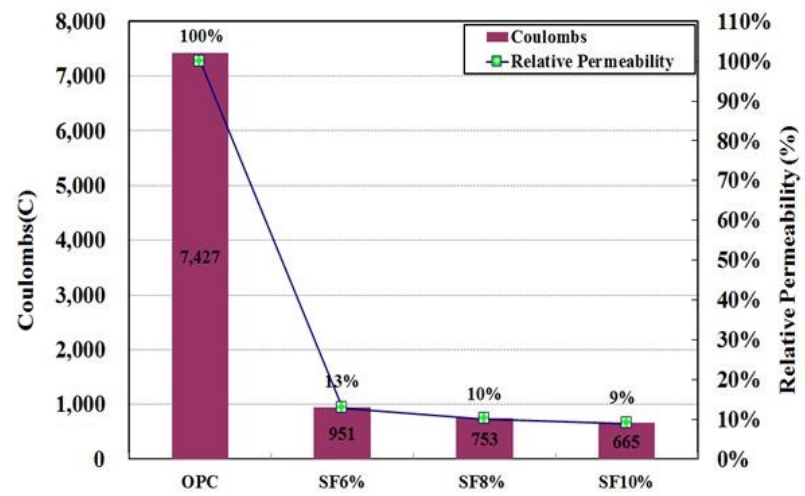

Figure 10 Results of shotcrtete RCPT

\section{Conclusions}

Hydrodemolition is a very effective method of surface preparation using high-pressure water jets. This paper describe on the test results of under-water hydrodemolition which was done on a pre-fabricated concrete basin. A very simple and economic method for repairing the damaged concrete structures is a using a sprayed concrete, which is called as shotcrete. This paper, also, describe on the test results of sprayed concrete for the rehabilitation of marine concrete structure.

(1) The objective of hydrodemolition mock-up test was to investigate and compare the hydrodemolition cutting performance in air and under water. The cutting shows that the higher nozzle height, the less cutting. The cutting depth was a little smaller at under water. However, the overall pattern and cutting depth was about the expected ranges. It was verified that the under-water hydrodemolition would be possible as expected.

(2) The compressive test results at 28 days and 56 days y increased as the content of silica fume increased. It was the highest at $10 \%$ of silica fume content as $62.7 \mathrm{MPa}$ at 56 days.

(3) The flexural test result at 28 days increased as the content of silica fume increased. It was the highest at 10 $\%$ of silica fume content as $8.8 \mathrm{MPa}$.

(4) The results of rapid chloride permeability test at 28 days was measured as 951, 753, 665 coulombs at 6,8 and $10 \%$ of silica fume content, respectively. The rapid chloride permeability test rated the control specimen as "high" while the silica fume specimen as "very low".

(5) The chloride diffusion coefficient was determined by Berke's method, and the durable life time against chloride was estimated by KCI, ACI and FIB methods. The life time was estimated as 62 years from KCI, 112 years from FIB code and 103 years from ACI codes.

\section{References}

1. AASHTO T277-07, Electrical Indication of Concrete's Ability to Resist Chloride Ion Penetration, American Association of State and Highway Transportation Officials, 2011

2. ACI 365.1R, Service-life prediction, State-of-theArt Report.

3. ASTM C 1202, Standard Test Method for Electrical Indication of Concrete's Ability to Resist Chloride Ion Penetration, ASTM Standard, Philadelphia, USA

4. Fib TG 5.6: Model Code for Service Life Design(SLD), working material.2004

5. KS F 2405, Standard Test Method for Compressive strength of Concrete, Korea Standard, 2010

6. Yang, C.C., L.C. Wang (2004), The diffusion characteristic of concrete with mineral admixtures between salt ponding test and accelerated chloride migration test, Materials Chemistry and Physics, Vol. 85, pp.266-272.

7. Yang, C.C., T.L. Weng (2003), Using charge passed to determine the chloride diffusion coefficient in mortar from accelerated chloride migration test, Construction and Building Materials, Vol. 17, pp.231-238. 